\title{
INFÂNCIA PLURAL: CRIANÇAS DO NOSSO TEMPO
}

[Martins Filho et al., Mediação: Porto Alegre, 2006. 120 p.]

Lourival José Martins Filho ${ }^{1}$

A obra "Infầncia Plural: crianças do nosso tempo" reúne pesquisas realizadas com e sobre crianças pequenas que freqüentam contextos de creches, pré-escolas e escolas.

Os estudos correspondem às discussões coletivas sobre a infância e a sua educação desenvolvidos no Programa de Pós-Graduação da Universidade Federal de Santa Catarina, os quais estão vinculados ao Núcleo de Estudos e Pesquisas da Pequena Infância/NUPEIN. Importa salientar e destacar, que o NUPEIN/UFSC vem em seu percurso de pesquisas e estudos considerando não só os problemas e as especificidades da educação infantil, mas, também, as reflexões teóricas e práticas de pesquisas empíricas, com vistas a ampliar o universo de intervenção junto às diferentes instituições educacionais e às idéias de infância e de criança.

O tema central do livro é a construção de conhecimentos sobre as infâncias de diversas crianças brasileiras. Descreve e analisa as crianças de várias idades em suas fantasias, em suas múltiplas linguagens, em seus constantes movimentos e em suas produções e interpretações da cultura humana. Sendo assim, o foco de análise que perpassa por diversos temas são as crianças e as apropriações, reinvenções e “reproduções interpretativas" (CORSARO, 2002).

\footnotetext{
${ }^{1}$ Professor de Prática de Ensino em Educação Infantil do Departamento de Metodologia do Ensino da Universidade do Estado de Santa Catarina/UDESC, Centro de Ciências da Educação/FAED. E-Mail: f2lourival@udesc.br
} 
Além disso, a obra busca defender a necessidade de construirmos novas teias de relações sociais entre adultos e crianças e estas entre si no interior dos contextos educativos. Como assevera Martins Filho (2005), as relações que se travam no interior das instituições de educação não podem ser sonhos com meras pretensões ou serem construídas somente com boa vontade, é preciso sim, transformá-las, amadurecê-las a partir de uma reflexão crítica sobre a infância plural: sobre o que pensam, como vivem e como brincam as crianças de nosso tempo.

Para tanto, os autores se inclinam no desafio de alertar para a necessidade de desenvolver-se uma base de discussão teórica e metodológica para a análise das expressões infantis, tendo como estratégia a observação das próprias crianças e suas experiências de vida nos contextos de educação coletiva. Da mesma forma propõem entrelaçar os fios interrelacionais entre as crianças e as outras pessoas, compreendendo que "cada ser humano entra em contato com o ambiente e a cultura construída coletivamente, socialmente; acumula experiências; seleciona as mais significativas para si e descarta as que considera indesejáveis" (SILVA FILHO, 2000, p.74). Neste sentido, que os textos que contemplam o livro apontam para as relações intra e intergeracionais que vão historicamente sendo produzidas e elaboradas pelas duas categorias de atores: adultos e crianças. Ao observar tais relações os autores revelam que os contextos educativos carregam no seu cotidiano encontros, desencontros e reencontros em que adultos e crianças desenvolvem múltiplas e complexas interações sociais, as quais são traçadas por sentidos e significados também diversos (MARTINS FILHO, 2005).

Os autores sinalizam a emergência de se construir processos sociais de alteridade seja nas práticas pedagógicas ou em metodologias de pesquisas com e sobre crianças. Neste caso, apontam que há certa urgência de superação dos dualismos criança/adulto e formação humana/reprodução social. 
Nos quatro textos é perceptível este esforço teórico-metodológico, no sentido de visualizar as infâncias nas vozes das crianças. Sendo assim, a obra é uma referência para pais, professores e especialistas que se interessam pelos estudos das infâncias. Principalmente pelos pesquisadores marcarem um compromisso político-pedagógico para com os problemas sociais, inerentes à educação de crianças; trata-se, portanto, de uma necessidade imperiosa de denúncia e anúncio sobre a situação das diversas infâncias e crianças. Como descreve Silva (2006, p. 6) ao prefaciar o livro, denúncia sobre a ineficácia das políticas públicas e a barbárie contra nossas crianças, sobretudo da classe trabalhadora empobrecida e anúncio de novos tratos teóricos, novas possibilidades de políticas públicas para as crianças e suas famílias.

O primeiro capítulo de Altino José Martins Filho, intitulado "Crianças e Adultos: marcas de uma relação" aponta indicações necessárias para se pensar sobre as formas dos processos de socialização na creche, na perspectiva de considerar as crianças sujeitos sociais e autores de seus processos sociais e culturais. Sua perspectiva situa-se no campo da Sociologia da Infância e da Pedagogia da Infância, procura travar um diálogo entre dois campos de conhecimento, sinalizando uma tentativa de interpretação da importância atribuída à infância e a valorização dada aos seus membros - as crianças - como sujeitos que se encontram em desenvolvimento, assim como os adultos ou outras categorias geracionais.

Martins Filho (2006) concebe o conceito de socialização pela abordagem interpretativa, superando com isto a tradicional sociologia funcionalista. Com apoio da sociologia da infância define socialização como sendo "um processo de inserção de um sujeito em um determinado contexto sociocultural por intermédio das relações humanas ali travadas dentro das condições e limites que esse meio impõe" (Idem, p. 16). O autor em suas análises assevera que é se socializando com os outros que as crianças vão 
descobrindo as próprias especificidades, como também as especificidades dos que com ela convivem. Neste sentido, a construção da visão de mundo efetuada pela criança se faz com o auxílio dos elementos produzidos por sua contínua relação social com os pares e com os adultos, em contextos sociais que vão se interpondo. Pelas categorias de análise elaboradas, foi possível perceber que tanto nas relações de conflito e tensão, como nas de maior harmonia, adultos e crianças produzem representações simbólicas a respeito do mundo com o qual interagem e, no caso das crianças, a elaboração das culturas infantis.

Na seqüência o capítulo de Fernanda Carolina Dias Tristão, denominado "Sutil complexidade das práticas pedagógicas com bebês" sinaliza um olhar diferenciado com crianças-bebês que freqüentam creches públicas em Florianópolis. A autora questiona: “O que é ser professora de bebês?". Assim, ao tentar respondê-la, Fernanda Tristão realiza uma análise contundente para as práticas pedagógicas em creches. Traz uma nova perspectiva de como ser professora de bebês, a qual vai muito além das práticas pedagógicas baseadas no senso comum de apenas cuidado, guarda, proteção e/ou somente gosta de crianças. Defende seriamente uma pedagogia para a infância que considere as crianças-bebês como seres integrais.

Assim, contextualiza suas idéias propondo que as professoras de crianças-bebês olhem, observem, e sentem os meninos e meninas dos grupos pelos quais são responsáveis, “aprendendo a respeitar seus ritmos e suas cadências, de forma a não se deixarem levar pela voracidade de uma rotina que automatiza ações e homogeneíza pessoas" (TRISTÃO, 2006, p.51). A análise do material coletado em um berçário indicou que o trabalho pedagógico realizado com meninas e meninos está marcado pela sutileza das ações presentes nas relações entre professora e crianças. Estas atitudes nem sempre são percebidas dentro da rotina diária, mas são determinantes na caracterização 
desta profissão. Esta sutileza está imbuída de uma complexidade que implica na percepção de cada uma das crianças, tendo como pano de fundo o papel da educação e das docentes para a humanização dos pequenos.

Na sequência, o capítulo escrito por Ilona Patrícia Freire Rech, denominado “A hora da atividade no cotidiano das instituições", apresenta um estudo focando suas análises nas professoras e nas crianças, na expectativa de compreender um momento específico da rotina da creche: "a hora da atividade".

A partir dos pressupostos da pedagogia italiana, Ilona levanta questionamentos sobre a estrutura e o modo de funcionamento das instituições, horários de entrada e saída, higiene, atividades e alimentação. Com base em uma analise minuciosa sobre estas rotinas no cotidiano da educação infantil, considera possível pensar o "tempo e o espaço" das crianças nas instituições.

Por fim, o último capítulo é de Maria Luiza Schneider, intitulado "Posso brincar professora?" O texto faz referências às escolas de ensino fundamental, especificamente os anos iniciais. A autora procura desenvolver uma compreensão de infância e brincadeira trazendo para a cena das discussões as vozes das crianças. Portanto, aborda a necessidade de um trabalho coletivo dos professores e de práticas pedagógicas realizadas na educação da infância que contemple os espaços de brincar. A partir de sua entrada nos estudos do enfoque histórico-cultural, Schneider (2006) realiza entrevistas com crianças e professores para saber as formas e os espaços onde acontecem as brincadeiras das crianças e como estas são constituídas nas relações sociais estabelecidas no contexto escolar. Entre as dificuldades encontradas estão a manifestação de resquícios de uma cultura escolar tradicional aliada a uma formação docente precária quanto a esta temática. As crianças traduzem o brincar como um modo de dizer, ou seja, uma forma de expressar-se, nem sempre consentida, ouvida ou mesmo 
valorizada. Segundo a autora, pode-se dizer que a criança brinca, muitas vezes apesar da escola e encontra modos de manifestar-se, de aprender e se desenvolver. Entretanto, a escola pode tornar-se um espaço de inesgotáveis possibilidades para a criança e o desenvolvimento de seu psiquismo, se desenvolver projetos que se preocupem em ouvir a criança, envolvendo temas como a participação infantil, seja nas discussões e reflexões que dizem respeito aos seus direitos e sobre as decisões da escola de modo geral.

Os textos que contemplam a obra desafiam-nos a pensar em desenvolver uma pedagogia das relações sociais, dando oportunidade de ouvirmos as crianças para se compreender os diversos jeitos de elas se pôr no mundo. Além, é claro, de apresentar elementos teóricos e práticos para conhecermos as infâncias plurais, crianças que são diversas e que vivem em diferentes contextos sociais.

\section{Referências}

CORSARO, William. A reprodução interpretativa no brincar ao "faz-de-conta" das Crianças. Educação, Sociedade e Culturas. Edições Afrontamento, LTDA: Porto, Portugal, no 17, p. 113-134, 2002.

MARTINS FILHO, Altino José. Crianças e adultos na creche: marcas de uma relação. Florianópolis, Dissertação 2005, 185p. (Mestrado em Educação) Curso de PósGraduação em Educação, Universidade Federal de Santa Catarina.

SILVA FILHO, João Josué da. Computadores: super-heróis ou vilões? Florianópolis: UFSC, Centro de Ciências na Educação, Núcleo de Publicações, 2000. 200p. 
Livro Resenhado:

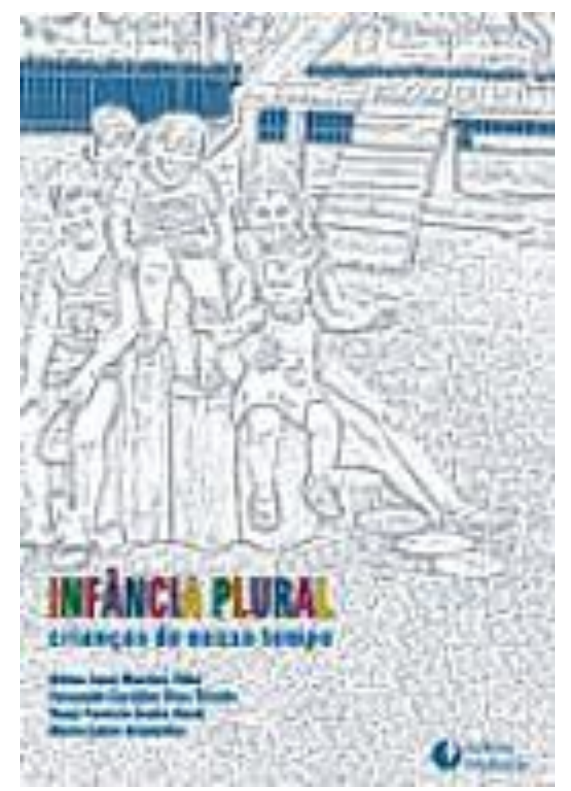

Data de recebimento: $28 / 07 / 2010$

Data de aceite: 24/08/2010 